\title{
Acute-Withdrawal Restless Legs Syndrome Following Abrupt Cessation of Short-Term Tramadol
}

\author{
Young-Min Park ${ }^{\circledR}$, Hye Kyeong Park ${ }^{2}$, Leen Kim³ ${ }^{3}$, Heon-Jeong Lee ${ }^{3}$, and Seung-Gul Kang ${ }^{4}$ \\ ${ }^{1}$ Department of Psychiatry, Ilsan Paik Hospital, Inje University College of Medicine, Goyang, Republic of Korea \\ ${ }^{2}$ Department of Internal Medicine, Ilsan Paik Hospital, Inje University College of Medicine, Goyang, Republic of Korea \\ ${ }^{3}$ Department of Psychiatry, Korea University College of Medicine, Seoul, Republic of Korea \\ ${ }^{4}$ Department of Psychiatry, Gachon University School of Medicine, Incheon, Republic of Korea
}

We report a young man who had received tramadol for pain control and experienced an uncomfortable sensation in both legs immediately after tramadol withdrawal that worsened at rest and at night, and which could be relieved only by moving the legs. He suffered from insomnia and paced up and down in his house every night. Readministration of tramadol dramatically resolved his symptoms of restless legs syndrome (RLS), but they reappeared after tramadol withdrawal. Tramadol was therefore replaced with ropinirole, which was discontinued after several weeks, and there was no recurrence of his RLS symptoms. This patient appeared to have developed tramadol-withdrawal-induced RLS, and this case report emphasizes the importance of monitoring for withdrawal-type symptoms like RLS when tramadol intake is being stopped.

Psychiatry Investig 2014;11(2):204-206

Key Words Tramadol, Restless legs syndrome, Adverse effect, Withdrawal symptoms.

\section{INTRODUCTION}

Tramadol is a synthetic 4-phenyl-piperidine analogue of codeine, and is a central analgesic mediated by a combination of mu-opioid agonist effects and norepinephrine and serotonin-reuptake inhibition. ${ }^{1-3}$ However, when stopping tramadol intake, several researchers have documented a withdrawal-like symptomatology. ${ }^{1-4}$

In this paper, we present a case that developed restless legs syndrome (RLS) following cessation of tramadol intake, which very likely was related to a withdrawal-like symptomatology.

\section{CASE}

A 38-year-old Korean male was admitted to the Department of Pulmonology due to pneumonia and parapneumonic effusion. He complained of severe left pleuritic pain and dys-

Received: April 5, 2013 Revised: June 28, 2013

Accepted: July 7, 2013 Available online: April 11, 2014

$\triangle$ Correspondence: Young-Min Park, MD, PhD

Department of Psychiatry, Ilsan Paik Hospital, Inje University College of Medicine, 170 Juhwa-ro, Ilsanseo-gu, Goyang 411-706, Republic of Korea

Tel: +82-31-910-7260, Fax: +82-31-910-7268

E-mail: medipark@hanmail.net

(a) This is an Open Access article distributed under the terms of the Creative Commons Attribution Non-Commercial License (http://creativecommons.org/licenses/bync/3.0) which permits unrestricted non-commercial use, distribution, and reproduction in any medium, provided the original work is properly cited. pnea with large amount of parapneumonic effusion. Thus, he had been treated by chest-tube insertion with antibiotics and an analgesic (tramadol at $50 \mathrm{mg}$ t.i.d.) for three weeks. His symptomatology had largely resolved after 3 weeks of hospital treatment, and so he was discharged to day-clinic treatment. Following discharge, tramadol was discontinued because his pain had disappeared. However, from the first night after tramadol withdrawal he experienced an uncomfortable sensation in both legs that worsened at rest and at night, and which could be relieved only by moving the legs. He suffered from insomnia and paced up and down in his house every night. He met the diagnostic criteria for RLS published by the International RLS Study Group. ${ }^{5}$ His doctor referred him for a psychiatric consultation.

The patient did not have any other disease related to secondary RLS. He also had no brain disease, and his only medication was cefixime. All of his routine laboratory parameters were within normal limits. The severity of his RLS symptoms was scored as 34 points on the RLS rating scale. ${ }^{6}$ Tramadol (50 $\mathrm{mg}$ ) was readministered at nighttime in order to confirm tramadol-withdrawal-induced RLS in a psychiatry department, which dramatically resolved his RLS symptoms. The patient subsequently attempted withdrawal of the 50-mg tramadol himself, which resulted in the recurrence of his RLS symptoms, prompting him to readminister tramadol. At a follow- 
up visit after 4 days his tramadol was replaced with ropinirole and clonazepam, which reversed his RLS symptoms. Ropinirole and clonazepam administration was discontinued after several weeks, and there was no recurrence of his RLS symptoms.

\section{DISCUSSION}

The symptoms of tramadol withdrawal are anxiety and restlessness, autonomic dysfunction, abdominal cramping, diarrhea, sleeplessness, migraine-like headaches, and myoclonic activity of the extremities. ${ }^{7,8}$ There are also reports of RLS as a complication of withdrawal from opiates such as methadone, heroin, fentanyl, and tramadol., ${ }^{4,-10}$

The present case had no history of RLS symptoms or insomnia, with his RLS symptoms beginning immediately after the abrupt cessation of tramadol therapy. Based on the Naranjo probability scale, ${ }^{11}$ the present RLS strongly suggests a close relationship to the previous intake of tramadol. In addition, rechallenge with tramadol (50 mg once a day) made his RLS symptoms disappear. The physical examination and laboratory findings of our patient revealed no evidence of any of the known forms of secondary RLS or of a comorbid organic disorder. It is therefore likely that the withdrawal of tramadol was responsible for inducing his RLS.

Some studies have found that opioids such as oxycodone and methadone are effective at treating RLS. ${ }^{12,13}$ Other studies also have reported RLS-like withdrawal symptoms following opioids such as methadone, while it was demonstrated conclusvely that adding another opioid as a treatment option relieved symtoms. In addition, PET scans have shown that the post-synaptic binding of ligand to the opioid receptor is inversely proportional to the severity of RLS symptoms in areas serving the medial pain system. ${ }^{14,15}$ These observations imply that opioids are involved in the pathophysiology of RLS. Moreover, stimulation of mu-opioid receptors increases dopamine release from dopaminergic neurons in some brain regions. ${ }^{10,16,17}$ Thus, mu-receptor agonists such as tramadol may increase the tone of endogenous dopamine release, resulting in a decreased sensitivity of dopamine receptors to adaptation., ${ }^{9,10,17}$ However, a compensatory overshoot of the NMDA receptor following the intake of long-term opioid can also induce RLS., ${ }^{4}$ In addition, Freye and Levy reported that diffuse musculoskeletal related pain and RLS following abrupt cessation of longterm use of tramadol were treated with dextromethorphan, ${ }^{4}$ which is an NMDA-receptor antagonist. ${ }^{19}$ Thus, the pathophysiology of acute-withdrawal RLS following abrupt cessation of tramadol remains a matter of controversy.

In conclusion, even after a medium potent analgesic such as tramadol with mixed opioid agonist, as well as inhibitory serotonergic and noradrenergic reuptake mechanism, with- drawal may develop following cessation of the agent. ${ }^{4,20,21} \mathrm{~Pa}$ tients therefore, should be monitored closely even after an analgesic, which in general is considered a safe drug.

\section{Acknowledgments}

This study was supported by a grant from National Research Foundation of Korea (NRF), funded by Ministry of Education and Science Technology (MEST) (2011-0010562).

\section{REFERENCES}

1. Dayer P, Desmeules J, Collart L. Pharmacology of tramadol. Drugs 1997;53(Suppl 2):18-24.

2. Desmeules JA, Piguet V, Collart L, Dayer P. Contribution of monoaminergic modulation to the analgesic effect of tramadol. Br J Clin Pharmacol 1996;41:7-12.

3. Lanier RK, Lofwall MR, Mintzer MZ, Bigelow GE, Strain EC. Physical dependence potential of daily tramadol dosing in humans. Psychopharmacology (Berl) 2010;211:457-466.

4. Freye E, Levy J. Acute abstinence syndrome following abrupt cessation of long-term use of tramadol (Ultram $\left.{ }^{\circledR}\right)$ : a case study. Eur J Pain 2000;4: 307-311.

5. Allen RP, Picchietti D, Hening WA, Trenkwalder C, Walters AS, Montplaisi J, et al. Restless legs syndrome: diagnostic criteria, special considerations, and epidemiology. A report from the restless legs syndrome diagnosis and epidemiology workshop at the National Institutes of Health. Sleep Med 2003;4:101-119.

6. Walters AS, LeBrocq C, Dhar A, Hening W, Rosen R, Allen RP, et al. Validation of the International Restless Legs Syndrome Study Group rating scale for restless legs syndrome. Sleep Med 2003;4:121-132.

7. Barsotti CE, Mycyk MB, Reyes J. Withdrawal syndrome from tramadol hydrochloride. Am J Emerg Med 2003;21:87-88.

8. Thomas AN, Suresh M. Opiate withdrawal after tramadol and patientcontrolled analgesia. Anaesthesia 2000;55:826-827.

9. Scherbaum N, Stüper B, Bonnet U, Gastpar M. Transient restless legslike syndrome as a complication of opiate withrawal. Pharmacopsychiatry 2003;36:70-72.

10. Park YM, Cho JH, Lim YS, Lee HJ, Kang SG, Kim L. The withdrawal from TDF therapy could induce transient RLS. Prog Neuropsychopharmacol Biol Psychiatry 2010;34:419-420.

11. Naranjo CA, Busto U, Sellers EM, Sandor P, Ruiz I, Roberts EA, et al. A method for estimating the probability of adverse drug reactions. Clin Pharmacol Ther 1981;30:239-245.

12. Walters AS, Wagner ML, Hening WA, Grasing K, Mills R, Chokroverty $S$, et al. Successful treatment of the idiopathic restless legs syndrome in a randomized double-blind trial of oxycodone versus placebo. Sleep 1993;16:327-332.

13. Walters AS, Winkelmann J, Trenkwalder C, Fry JM, Kataria V, Wagner $\mathrm{M}$, et al. Long-term follow-up on restless legs syndrome patients treated with opioids. Mov Disord 2001;16:1105-1109.

14. von Spiczak S, Whone AL, Hammers A, Asselin MC, Turkheimer F, Tings T, et al. The role of opioids in restless legs syndrome: an [11C]diprenorphine PET study. Brain 2005;128:906-917.

15. Walters AS, Ondo WG, Zhu W, Le W. Does the endogenous opiate system play a role in the Restless Legs Syndrome? A pilot post-mortem study. J Neurol Sci 2009;279:62-65.

16. Morris BJ, Johnston HM. A role for hippocampal opioids in long-term functional plasticity. Trends Neurosci 1995;18:350-355.

17. Walker JM, Thompson LA, Frascella J, Friederich MW. Opposite effects of mu and kappa opiates on the firing-rate of dopamine cells in the substantia nigra of the rat. Eur J Pharmacol 1987;134:53-59.

18. Manning BH, Mao J, Frenk H, Price DD, Mayer DJ. Continuous co-administration of dextromethorphan or MK-801 with morphine: attenuation of morphine dependence and naloxone-reversible attenuation of 
morphine tolerance. Pain 1996;67:79-88

19. Reissig CJ, Carter LP, Johnson MW, Mintzer MZ, Klinedinst MA, Griffiths RR. High doses of dextromethorphan, an NMDA antagonist, produce effects similar to classic hallucinogens. Psychopharmacology (Berl) 2012;223:1-15.
20. Jensen JB. Dependence after treatment with tramadol. Ugeskr Laeger 1997;159:785.

21. Miranda HF, Pinardi G. Antinociception, tolerance, and physical dependence comparison between morphine and tramadol. Pharmaol Biochem Behav 1998;61:357-360. 